International Journal of Engineering \& Technology, $7(3.15)(2018) 277-279$
SPC
Website: www.sciencepubco.com/index.php/IJET
Research paper

\title{
Turbogenerator: Part 1: Simulation
}

\author{
Lev Yu. Lezhnev, Alexey P. Tatarnikov, Arcady A. Skvortsov, Igor A. Papkin, \\ Aleksandr S. Nekrasov
}

Moscow Polytechnic University, Russia, 107023, Moscow, Bolshaya Semenovskaya Str., 38

\begin{abstract}
The article describes the process of developing a turbogenerator for power plants of small and distributed power generation. The analysis of the component base for the turbogenerator was carried out, and thereof a comparative analysis of possible technical solutions was conducted. The work considered the installation variants of a turbogenerator in the exhaust system, an electric machine of a turbogenerator, types of turbines of a generator. A mathematical model for computation of the output effective and geometric parameters of a turbogenerator was described. The results of computational analysis were presented, and the parameters of the turbogenerator being developed were selected. Based on the results of the work done the conclusions were made
\end{abstract}

Keywords : recovery system, turbogenerator, mathematical model, heat engine, small powert.

\section{Introduction}

To date, the base of small and distributed power in the world is the diesel-generator and cogeneration plants. The main types of engines of such power plants are piston diesel and gas internal combustion engines. Currently, restrictions on harmful emissions for power plants are lower than those for automobile engines, but there are tendencies to tighten these requirements. A lot of research has been done in this area, including the research of exhaust gases energy recovery systems. The application of recovery systems makes it possible to increase the overall efficiency of the entire plant, thereby reducing the unit cost of electric power and the specific fuel consumption, and reducing the harmful emissions. At the previous stage of work, a comparative evaluation of the existing research areas in the field of recovery systems was performed, on the basis of which the field of the turbogenerators was chosen. The recovery systems are aimed at increasing the efficiency of power units, and today they allow increasing the efficiency of power plants by $10-12 \%$, which is significant, taking into account the price increase for hydrocarbon fuels and the tightening of environmental standards ${ }^{[1-4]}$.

High-speed turbogenerator units can be used for most heat recovery systems, both for heat engines and industrial heat. The generated electrical energy enters the grid or charges buffer energy storages to be used later ${ }^{[5]}$.

Comparative analysis of possible technical solutions

Within the research, a turbogenerator was chosen as the basic concept of the exhaust gas energy recovery system of small and distributed power plants. Then a comparative analysis of the recovery system components on the basis of a turbogenerator was carried out. The turbogenerator consisted of a turbine, an electrical machine, turbogenerator control components, and constructive elements. When developing the recovery system concept, several constructive solutions were considered:

- disposition of a turbogenerator in the exhaust system;

- types of turbine connection units;

- types of electric machines.
Disposition of a turbogenerator in the exhaust system

The disposition of the turbogenerator can be implemented in two schemes: sequential and parallel. Each of the schemes has its advantages and disadvantages.

The sequential scheme of a turbogenerator is the easiest, since the turbogenerator is installed inside the exhaust system, and the turbine exhaust exit is in the exhaust pipe. This scheme makes the arrangement and installation of the turbogenerator easier, ensures the constant co-operation of the turbogenerator with the power plant, and eliminates additional hydraulic losses in the shutters, and therefore is more preferable. However, this system has a number of disadvantages, such as the inability to operate the power plant due to the system's malfunction, the impossibility of performing the necessary maintenance with the power plant operating and also a possible expanding of the rotor speed beyond the permissible parameters along with a sudden drop in load. Therefore the bypass valve or emergency braking device installing is recommended.

The parallel setting allows controlling the exhaust gas flow through the turbogenerator, controlling the power of the turbogenerator, performing maintenance on the operating unit, operating the power plant with the turbine generator switched off, and, in case of emergency, shutting off the exhaust gas supply to the turbogenerator, thereby reducing possible damage and cost of repairs, and also increasing the efficiency and productivity of the power plant ${ }^{[6-8]}$.

This scheme also has a number of disadvantages, such as the increase in cost due to the need for high-temperature mass-size parameters, as well as the increase in the number of shutters, the design complexity and the increase in discharge resistance due to hydraulic losses.

\section{Types of turbine connection units \\ 1) Centripetal radial turbines}

A wide distribution in turbochargers of low power was obtained by centripetal radial turbines, which allow developing compact and fairly simple turbine units and have an acceptable priceefficiency ratio. 
The exhaust gases move along the radial branch pipe and enter the nozzle, where the exhaust gases expand and increase their speed. Nozzle is manufactured with guide blades with a tapered section where the exhaust gases expand and the gas flow rate increases. The relative speed of the gas depends not only on the expansion but also on the inertia forces, which in the centripetal turbine slow the gas flow in the blade channels of the impeller. To overcome the inhibitory effect of centrifugal forces when moving gas from the periphery to the center of the impeller, centripetal turbines are always reactive, with an average reactivity $\rho=0,45 \div 0,55$. Small differences in gas pressure in the impeller (for small $\rho$ ) may not be sufficient to overcome the centrifugal forces, and then the relative velocity of the gas at the output can become zero.

Another parameter of the turbine is the ratio of the flow area of the nozzle to its radius $\mathrm{A} / \mathrm{R}$, or Area/Radius.

The effect of the turbine shell's $\mathrm{A} / \mathrm{R}$ on its performance is very significant. Actually, this parameter determines the amount of exhaust gas flow a turbine is capable to pass through. Using a smaller $\mathrm{A} / \mathrm{R}$ value, it is possible to increase the airflow rate in the turbine shell, and it becomes possible to increase the turbine power in the low load range. However, the low turbine shell's A/R has its disadvantages. Gases fall on the impeller almost along the tangential trajectory, which significantly reduces the maximum flow of gases that can pass through the turbine wheel. In addition, at smaller values of $\mathrm{A} / \mathrm{R}$, the gas back pressure is increased before the turbine.

\section{Axial turbines}

When the exhaust gas flow through the turbine increases (for example on diesel locomotive or marine engines), the axial turbines are to be used which, at high gas flow rates, can provide higher efficiency. This is due to the fact that for axial turbines designed for a low exhaust gas flow rate the turbine blades should be small because of the increase in losses. The cost of axial turbines is much higher, due to the complex manufacturing technology. For our research, the turbine generator power was up to $10 \mathrm{~kW}$, and axial turbines will not be considered further.

\section{Types of electrical machines used}

During the development of the concept of a turbogenerator, an analysis of various types of electric machines was conducted, of which the synchronous machine with permanent magnets was chosen as the most preferable. High reliability and good handling allow using this type of electric machines in the industry, especially in the nodes with a wide range of speed regimes, and a high rate of start-up.

Electric engines and generators of this type combine the best qualities of alternating and direct current machines, which determines their advantages

- a wide range of speed changes;

- contactless and missing nodes that require frequent maintenance (of a collector);

- a possibility to be used in an explosive and aggressive environment;

- high overload capacity;

- high energy performance (efficiency above 90\%)

- high specific moment;

- control effectiveness;

- availability for purchase;

- long service life and high reliability due to the absence of sliding electrical contacts.

The disadvantages are:

- high cost, due to the use of expensive permanent magnets in the rotor design;

- relatively complex structure of the electrical machine;

- the need for an additional system for protection against short and turn-to-turn closure.

Machines with permanent magnets have a high specific moment and long service life, have a high overload capacity and high energy and efficient performance, both in the motor and generator modes. Therefore, it was decided to use an electric machine with permanent magnets as an electric machine for a turbogenerator.

Development of the simulation model of a turbogenerator

After choosing the concept of a turbogenerator, it was necessary to conduct a computational analysis. Therefore a mathematical model of the turbogenerator was developed. The task of the project was to develop a turbogenerator for an internal combustion engine with a capacity of at least $100 \mathrm{~kW}$. A turbogenerator must produce from 5 to $10 \mathrm{~kW}$ of electric power with a specific fuel consumption reduction of at least $7 \%$ compared to the engine chosen. According to the research conducted, the recovery systems can convert up to $12-15 \%$ of the exhaust power [6-8]. Therefore, a ZMZ409 engine with a capacity of $105 \mathrm{~kW}$ was selected, which will be used as a gas generator in testing the turbogenerator.

The simulation model of a turbogenerator consists of two blocks, combined into one model. The first block is responsible for mathematical modeling and calculation of the geometric and power parameters of the turbine, the second block is responsible for calculating the generator parameters.

\section{Turbine computation module}

The methods of calculation for radial-axial turbines were used for developing the turbogenerator turbine computation module. To calculate the parameters of the turbine, the preliminary effective parameters of the turbine wheel, the parameters of the exhaust gases (temperature, flow rate, gas constant, heat capacity, etc.) were set. Based on the source data, the calculation and determination of the geometric parameters of the turbine were carried out, and the effective parameters set at the beginning of the computation were corrected.

\section{Electric Machine Computation}

A modular mathematical model of Matlab was used to calculate a synchronous electric machine with excitation from permanent magnets. The computation unit is a model of a classical synchronous machine with permanent magnets, in which the saturation of the magnetic circuit is not taken into account, since such machines have, as a rule, an increased air gap.

The simulation model of a turbogenerator consisting of two computation units allows calculating first the geometric and energy parameters of a turbine depending on the initial parameters of the exhaust gases and then calculating the parameters of a synchronous electric machine to provide the required parameters of the turbogenerator.

\section{Computational analysis}

For computational analysis, the results of measuring the loading characteristics, change of EG pressure and expense-temperature parameters of the system of release of piston ICE were used as the initial data.

Due to the fact that the turbogenerator was designed for operation at stationary power plants of small and distributed power, the turbine parameters were calculated for the maximum rotations per minute that provide the maximum gas flow.

The results of the analysis of the maximum rotations per minute of the internal combustion engine at full power allowed calculating the power of the turbogenerator. The performance diagram of the dependence of power on the parameters of the exhaust gases before and after the catalyst neutralizer is shown in Fig. 1. 


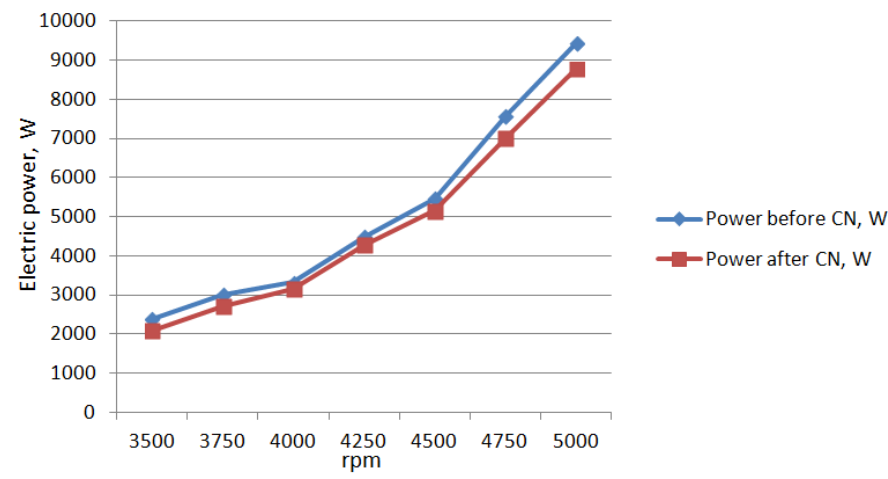

Figure 1: Electric power of the turbogenerator before and after the catalyst neutralizer.

To obtain this power, according to the calculated data, a turbine was used with the following parameters:

- a diameter of a turbine wheel

$$
\begin{gathered}
\mathrm{D}_{1 \mathrm{t}}=53 \mathrm{~mm} \\
\mathrm{D}_{2 \mathrm{t}}=67 \mathrm{~mm} \\
\mathrm{D}_{\text {Bт }}=18 \mathrm{~mm} \\
\mathrm{~b}_{1 \mathrm{t}}=10 \mathrm{~mm} \\
\mathrm{Z}=9-12 \\
\mathrm{H}_{\mathrm{u}}=0.8 \\
\eta_{\mathrm{i}}=0.7 \\
\eta_{\mathrm{e}}=0.64
\end{gathered}
$$$$
\text { (turbine }
$$

- internal efficiency of the turbine

- net efficiency of the turbine

\section{Conclusions}

The conducted research at this stage allows studying modern trends of recovery systems, determining the level of technology in this field of research, choosing the directions of research and the optimal version of the turbogenerator. Based on the preliminary computational analysis the technical shape was determined.

To date, high-speed electric machines on magnetic (or gas) bearings can have rotational speeds at the turbo-rotor speed level. The use of rare-earth metals in the manufacture of electric machine rotors makes it possible to obtain high specific and effective indices.

The study has shown that in the power range of turbines from 5 to $10 \mathrm{~kW}$, the use of radial centripetal turbines is most effective and economically feasible due to their lower cost at given typical sizes compared to axial turbines.

The control system of the turbogenerator will be built on microprocessor blocks of industrial analogue-digital controllers due to their wide application, high speed of operation and reliability.

Based on the results of the analytical and computational studies, the technical appearance of the turbogenerator was determined and a schematic diagram was developed. Based on the developed conceptual scheme, in the course of further research, a three-dimensional model of a turbogenerator will be developed, the necessary calculations, design documentation, and a turbogenerator will also be made.

\section{Acknowledgement}

This work was prepared within the framework of the agreement No. 14.574.21.0154 of September 26, 2017, on granting a financial support of the Ministry of Education and Science of the Russian Federation. Unique identifier of applied scientific research RFMEFI57417X0154.

\section{References}

[1] Thompson, I., Spence, S., McCartan, C., Thornhill D. and Talbot-Weiss, J. (2011). "Investigations Into the Performance of a Turbogenerated Biogas Engine During Speed Transients" Proc. ASME Turbo Expo, Vancouver. Canada.

[2] Shiraishi, K. and Ono, Y. (20047). Hybrid Turbocharger with Integrated High Speed Motor-generator, Mitsubishi Heavy Industries, Ltd. Technical Review, 44(1)

[3] Thompson, I. (2009). "Investigation into the Effects of Turbocompounding", Differentiation Report. School of Mechanical and Aerospace Engineering, Queen's University Belfast, Northern Ireland, unpublished.

[4] Hountalas, D., Katsanos, C. and Lamaris, V. (2013). "Recovering Energy for the Diesel Engine Exhaust Using Mechanical and Electrical Turbocompounding", Proc. Soc. Automotive Engineers Int. World Congr., Detroit, USA, 2007. SAE Paper Number 2007-01-1563.

[5] Patent - CN103061869 (A) , MPK F02B37/04; F02B37/14; F16C32/04; F16D27/02; F16D48/06. Electric turbocharger/ Beijing Inst Technology, CN2013107071, 09.01.2013, 24.04.2013.

[6] Wei, W., Zhuge, W., Zhang, Y. and Yongsheng, (2010). "Comparative Study on Electric Turbo-Compounding Systems for Gasoline Engine Exhaust Energy Recovery", Proc. ASME Turbo Expo 2010: Power for Land, Sea, and Air (GT2010). Glasgow. UK. Paper no. GT2010-23204, pp. 531-539.

[7] Miction M. et al. (2006), "Switched Reluctance TurboGenerator for Exhaust Gas Energy Recovery", Proc. IEEE Power Electron. Motion Control Conf. Portoroz. Slovenia, pp. 18011807.

[8] Miction M. et al., (2007) "Modelling and Testing of a Turbogenerator System for Exhaust Gas Energy Recovery", Proc. Vehicle Power and Propulsion Conf., Arlington, USA, pp. 544-550. 